\title{
Statistical Modelling of Significant Wave Height: Inshore and Offshore Bonny River Estuary, Nigeria
}

\author{
Itolima Ologhadien \\ Department of Civil Engineering, Rivers State University of Science and Technology, \\ P.M.B, 5080, Nkpolu, Port Harcourt, Nigeria
}

\begin{abstract}
The selection of best - fit probability distribution is of fundamental importance in the design, planning, and operability studies for harbours, coastal and offshore structures and exploitation of coastal resources. A wrong choice of probability distribution could lead to either under - or over - estimation of design loads, which may have detrimental impacts on safety and project economy. Consequently the Inshore and Offshore wave data of Bonny River estuary, Nigeria was studied by fitting Rayleigh, 2- parameter Lognormal, Fisher - Tippett Type 1(FT-1), 2-parameter and 3-parameter Weibull probability distributions using probability paper method. The probability distributions were subjected to five model evaluation metrics; coefficient of determination $\left(\mathrm{R}^{2}\right)$, demeaned RMSE, normalizedRMSE, Scatter index (SI) and Performance scores index $\left(\mathrm{d}_{1}\right)$ and a scoring scheme was adopted on the basis of which the best - fit probability distribution for either Inshore of Offshore was selected. The results show that 2-parameter Lognormal distribution is the best -fit probability distribution for the Inshore station, seconded closely by Fisher - Tippett Type 1 and 3- parameter Weibull distributions. The results also show that Fisher - Tippett Type 1 is the best - fit probability distribution for the offshore station seconded closely by 3 - parameter Weibull distribution. This study will contribute to the development of the coastal zone and also a recipe for Integrated Coastal Zone Management of the Nigerian Gulf of Guinea.
\end{abstract}

Key words: Bonny river estuary, goodness of fit tests, integrated coastal zone management, significant wave height, probability distribution models.

DOI: $10.7176 / \mathrm{CER} / 11-4-08$

Publication date:May $31^{\text {st }} 2019$

\section{Introduction}

Ocean waves may be generated by wind stresses from the atmosphere, earthquakes, gravity of the earth and celestial bodies, cosmic forces, and surface tensions. These forces can impose enormous impacts upon coastal and offshore structures (WMO - No. 72). The calculation of these forces in extreme is done statistically using the linear wave theory to predict the height and periods of the extreme waves. The most important wave design parameter and the most studied statistical parameter, is the significant wave height $\mathrm{Hs}(\mathrm{m})$, defined as the average height of the highest one-third of the waves, i.e. if all wave heights measured from the record are arranged in descending order. It has been shown that certain assumptions, the probability distribution of wave heights can be described completely in terms of the significant wave height (HMSO - 256). Consequently, the long-term behaviour of Hs should enable us to derive inference concerning the long-term statistics of individual wave heights. In practice, various probability distributions are fitted to the significant wave height data and the one giving the best visual fit is accepted. The distributions that have received particular application to coastal and offshore engineering are Rayleigh, 2- and 3- parameter log-normal, 2- and 3-parameter Weibull and Extreme value distribution (the Fisher Tippett Type 1.

The WMO-No. 702( 1989) observed that 2-parameter Log-normal distribution is good fit, in the absence of seasonal cycle. It also observed that 3-parameter distribution gives better fit than the 2-parameter counterpart. Further, it asserted that Fisher-Tippett Type 1 distribution fits better to three-hourly data from the North Atlantic and North Sea.

The method of fitting the chosen distribution often involves the use of (i) probability paper (ii) Methods of Moments (MoM) and (iii) maximum likelihood estimates (ML).

The probability paper is a graph paper with non-linear scales on the probability and height axes. The probability distribution is fitted by putting a straight line through the plotted values, preferably using a spreadsheet. (e.g. Excel). The method is applicable to 2-parameter distributions. The probability paper method may be extended to fit, 3 - parameter distributions by plotting the data over a range of values of the third parameter to see which value gives the best fit to a straight-line by minimizing the residual variance or by maximizing the correlation coefficient.

The method of moments (MoMs) is an analytic method of estimating the parameters of a distribution. The MoMs is based on the simple idea, that since the moments of the distribution (mean, variance, skewness, etc.) depend upon the parameter values, estimate of these values can be obtained using estimates from the data of the mean, etc.

The method of maximum likelihood (MLE), consists of finding values for the distribution parameters, 
which maximize the likelihood that the observed data come from this distribution (WMO - No.72. 1989). Ochi(1982) observed that there is no probability distribution function that universally fits all long - term wave height data. The usual approach is to investigate a number of commonly used distributions and then adopt the one giving the best - fit. Accordingly, the method of probability paper based on probability plots and least squared is adopted. The distributions being investigated are two-parameter Log-normal, two and three parameter Weibull, the Fisher-Tippett Type 1(FT-1) and Rayleigh. The modelling of significant wave height has not been studied in the Nigerian Gulf of Guinea. Therefore, the objective of this research is the selection of best - fit distribution on the basis of five goodness - of - fit tests using the probability paper method. The modelling of long-term distribution of significant wave height is important for a wide range of activities including: exploitation of coastal resources, integrated coastal zone management (ICZM).

\subsection{Materials and Methods.}

\subsection{Data and Study Area}

The Inshore wave measurement station is situated near Bonny Island while the Offshore station is located near the Bonny Offshore Oil Production Platform at approximately $4^{\circ} 16^{\prime} \mathrm{N}$ and $7^{\circ} 19^{\prime} \mathrm{E}$. The coordinates of the Inshore station is at approximately $4^{\circ} 25.5^{\prime} \mathrm{N}$ and $7^{\circ} 8.6^{\prime} \mathrm{E}$ or at Nigerian National Grid co-ordinates $520200 \mathrm{E}$, $47250 \mathrm{~N}$. The water depths at inshore station and offshore station are $13 \mathrm{~m}$ and $20 \mathrm{~m}$ respectively. The astronomical tide is semi-diurnal. The maximum tidal range observed is 2.5 meters. Figure 1 shows the locations of the inshore and offshore wave measurement stations.

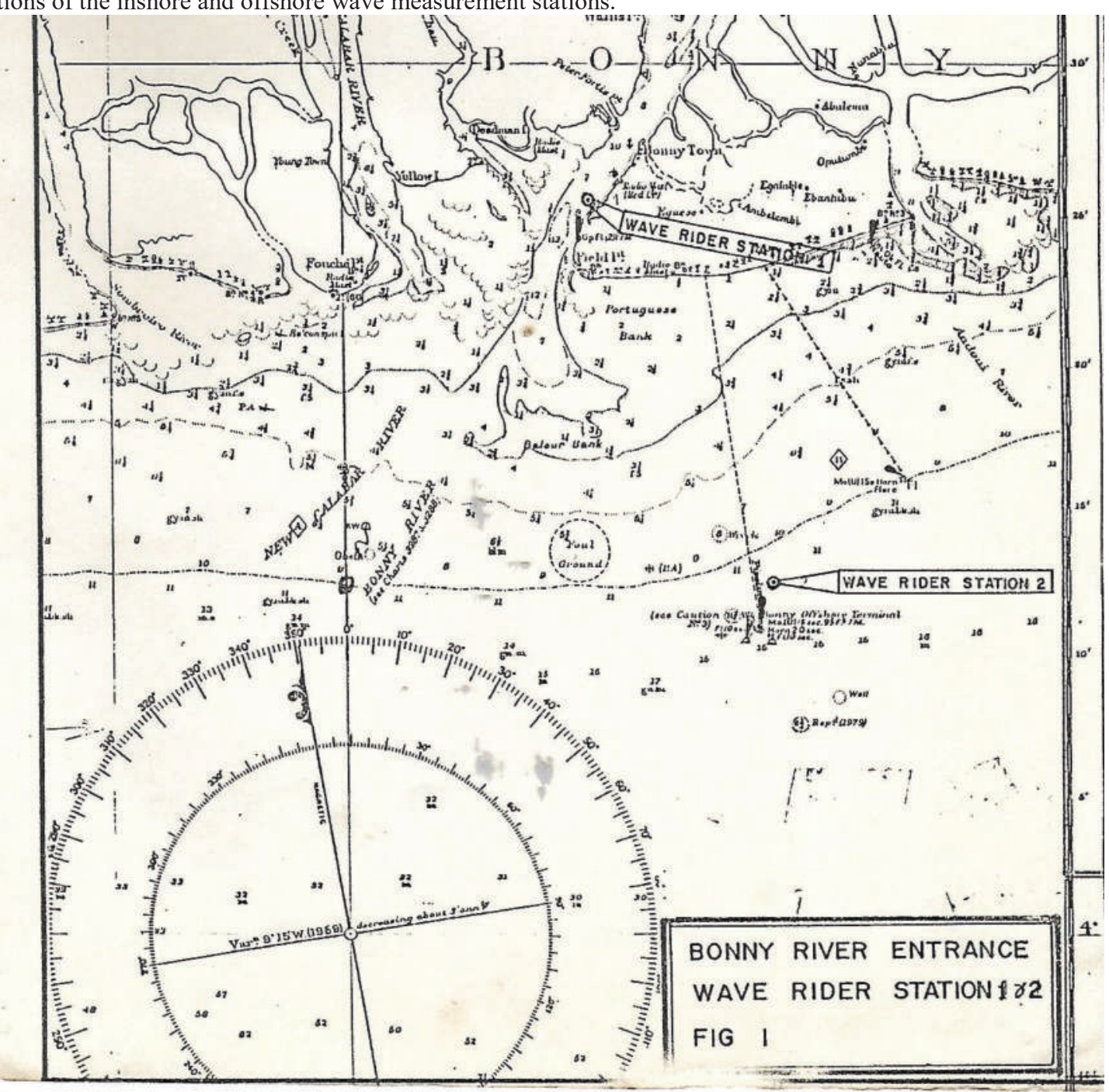

The wave height measuring system consist of a datawell waverider buoy with radio transmitter and a DIWAR (Digital Wave Receiver). The DIWAR is designed for the reception of the wave height measurement, transmitted by the waverider and direct communication with the Hp Vectra is via RS232 transmit and receive 
module. The unit consists of a radio receiver, phaselock for demodulator, anti- aliasing filter, A-D converter and RS232 communication port. The various onshore wave logging components are shown in Figure 2(Nigerian LNG - Annual Report, 1990).

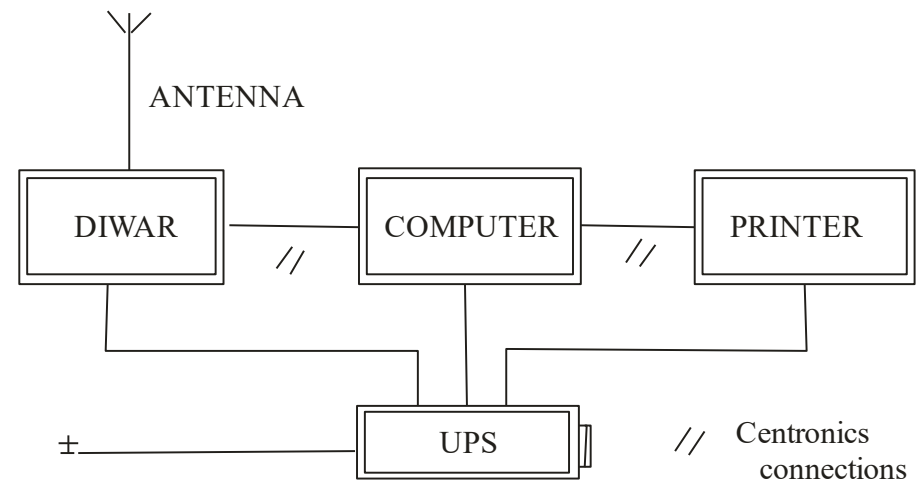

Figure 2: Onshore Wave Logging System

\subsection{Probability Distribution}

The probability distributions, Cumulative density functions, and probability plotting axes of the selected probability models are shown in Table 1.

Table 1: Probability Distribution Functions.

\begin{tabular}{|c|c|c|c|c|}
\hline \multirow[b]{2}{*}{$\begin{array}{l}\text { S/ } \\
\text { No. }\end{array}$} & \multirow{2}{*}{$\begin{array}{l}\text { Distribution of } \\
\text { random } \\
\text { variable } x\end{array}$} & \multirow[b]{2}{*}{ PDF and CDF } & \multicolumn{2}{|c|}{ Distribution Probability Plot } \\
\hline & & & $\mathrm{X}$ - axis & Y-axis \\
\hline 1. & Fisher- -Tippett & $F(H)=\exp \left[-\exp \left(\frac{H-A}{B}\right)\right]$ & $-\log [-\log (P)]$ & $\mathrm{Y}=\mathrm{H}$ \\
\hline 2. & Weibull(2) & $\begin{array}{l}f(H)=\left(\frac{K}{\alpha}\right)\left(\frac{H}{\alpha}\right)^{K-1} \exp \left[-\left(\frac{H}{\alpha}\right)^{\kappa}\right] \\
F(H)=1-\exp \left[-\left(\frac{H}{\alpha}\right)^{K}\right]\end{array}$ & $\log [-\log (1-P)]$ & $\log (H)$ \\
\hline 3. & Rayleigh & $\begin{array}{l}f(H)=\left(\frac{H}{\alpha^{2}}\right) \exp \left[-\frac{x^{2}}{2 \alpha^{2}}\right] \\
F(H)=1-\exp \left(\frac{-H^{2}}{2 \alpha}\right)\end{array}$ & $\log [-\log (1-P)]$ & $\log (H)$ \\
\hline 4. & Lognormal & $f(H)=\frac{1}{H \sqrt{2 \pi}} \exp \left[\frac{-\left(\log H-\mathrm{\iota}_{y}\right)^{2}}{2 \delta_{y}^{2}}\right]$ & $\phi^{-1}(P)$ & $\log (H)$ \\
\hline 5. & Weibull(3) & $\begin{array}{l}f(H)=\left(\frac{K}{\alpha}\right)\left(\frac{H-m}{\alpha}\right)^{K-1} \exp \left[-\left(\frac{H-m}{\alpha}\right)^{K}\right] \\
F(H)=1-\exp \left[-\left(\frac{H-m}{\alpha}\right)^{K}\right]\end{array}$ & $\log [-\log (1-P)]$ & $\log (H-A)$ \\
\hline
\end{tabular}

\subsection{Wave Evaluation Metrics}

Statistical metrics applicable to evaluation of wave models were used to assess the performance of the probability distributions. The metrics are coefficient of determination, demanded root mean square error (demeaned RMSE), Scatter Index (SI), Normalized root mean square error (NRMSE), and Performance Score index $\left(\mathrm{d}_{1}\right)$. For each of the measures given, Hso represents the observed significant wave heights, Hsp represents the predicted significant wave heights, $\mathrm{N}$ is the number of observations and $\bar{H}_{\text {os }}$ is mean significant wave height. The computational forms of the above metrics are:

(i) The bias estimate; $\mathrm{b}=1 / \mathrm{N} \sum(\mathrm{Hsp}-\mathrm{Hso})$ 
The RMSE is a measure of the residuals between the model predictions and measured observations, where larger

$$
\sqrt{\frac{1}{N-1} \sum(H s p-H s o-b)^{2}}
$$
number indicate greater variance. RMSE can range from zero to infinity and lower the value, the better the model. RMSE (demeaned) is RMSE estimate corrected for the bias, resulting in its equivalence to the standard deviation of the difference normalized (NRMSE) are RMSE estimates which include components of variance and bias (Ardhuin et al., 2010).

(iii) NRMSE - $\sqrt{\sum H_{S O}^{2}}$

By presenting the RMSE as unbiased, a more complete picture of the error distribution is provided (Chai and Draxler, 2014).

(iv) Scatter index (SI): $\mathrm{SI}=\frac{R M S E}{\overline{H S O}}$

The SI is a normalized measure of error, often reported as a percent. Low values of the SI are an indication of better model performance.

(v) Performance Score $\left(\mathrm{d}_{1}\right)$ gives a large overall performance scores. It is reported as the Willmott et al. (1985) index defines as the following:

Performance Scores $\left(\mathrm{d}_{1}\right)=1-\frac{\sum|H s p-H s o|}{\sum(|H s p-\overline{H s o}|+|H s o-\overline{H s o}|)}$

$\mathrm{d}_{1}$ is based on the absolute values of the errors and is less sensitive to errors concentrated in outliers compared to its original formulation. The $\mathrm{R}^{2}$ in Equation indicates the proportion of observed variation that can be explained by the model. The higher the value of $\mathrm{R}^{2}$, the more successful is the linear regression model in explaining the variation.

\section{Analysis, Results and Discussion \\ 3.1 Analysis}

Tables 2 and 3 show the probability distribution of inshore and offshore significant wave height calculations for $1989-1990$. The class intervals in Table 2 is $50 \mathrm{~mm}(0.05 \mathrm{~m})$ each. Ni in column 4 indicates, the total number of waves in each class interval per year. In column $5, \Sigma \mathrm{Ni}$ signifies the number of observations up to and including the present class interval. Column 6 gives the probability that any wave height $\mathrm{H}^{\prime}$ is equal to or less than a specified wave height $\mathrm{H}$, defined as $\mathrm{Q}\left(\mathrm{H}^{\prime}>\mathrm{H}\right)=1-\mathrm{P}$. The values in column 6 may be presented in equation form as;

$\mathrm{P}\left(\mathrm{H}^{\prime} \leq \mathrm{H}\right)=$ total number of data $=8,870,933$

Equation 6 is the empirical cumulative distribution function (CDF). Since the most robust relationship for both interpolation and extrapolation is a straight line, the CDF or the Plot of column 6 (probability) against wave height $\mathrm{H}$ is transformed into a linear model as:

$\mathrm{Y}=\alpha \mathrm{X}+\beta$

Where $\mathrm{Y}$ is the transformed probability axis, also called the reduced variate and $\mathrm{X}$ is the transformed wave height axis. The $\mathrm{X}$ and $\mathrm{Y}$ axes of the probability distributions used in the study are shown in Table 1. For normal distribution, each coordinate point is plotted as $\left(\mathrm{H}, \mathrm{z}=\Phi^{-1}\left(\mathrm{P}_{\mathrm{i}}\right)\right)$, where $\Phi^{-1}\left(\mathrm{P}_{\mathrm{i}}\right)$ is inverse function $\Phi^{-1}($. is calculated using the Ms Excel built-in function Norm. $\operatorname{Si} \operatorname{Inv}\left(\mathrm{P}_{\mathrm{i}}\right)$. In this way column $8\left(\mathrm{z}=\Phi^{-1}\left(\mathrm{P}_{\mathrm{i}}\right)\right.$ is plotted against $H$ (column 3). The coefficients $\alpha$ and $\beta$ are the slope and intercept of Equation 7, they represents the mean and standard deviation, and in turn can be used to calculate the distribution parameters. Accordingly for Log-normal distribution, $\mathrm{z}=\Phi^{-1}(\mathrm{P})$ is plotted against $\mathrm{LnH}$. In the case of Fisher-Tippett 1(FT-1) distribution, the reduced variate $\mathrm{Y}=-\mathrm{Ln}\left(\mathrm{Ln} \mathrm{P}^{-1} \mathrm{i}\right)$. In column $10(\mathrm{G})$ is plotted against $\mathrm{H}$ (column 3). For the 2-parameter Weibull distribution, column 9 is plotted against $x=\operatorname{Ln}(-\operatorname{Ln}(Q))$; the $Q-$ value are given column 7. In the case of three-parameter Weibull distribution, $\mathrm{LN}(\mathrm{H}-\mathrm{A})$ is plotted against $\operatorname{Ln}\left(-\operatorname{Ln}\left(1-\mathrm{P}_{\mathrm{i}}\right)\right.$, the parameter " $\mathrm{A}$ " is chosen by trial, until the best straight line is obtained. The above analysis is repeated for Table 3 . 
Table 2: Probability Distribution of Inshore Hs. Calculations (1989 - 1990)

\begin{tabular}{|c|c|c|c|c|c|c|c|c|c|c|c|}
\hline $\begin{array}{r}\mathrm{S} / \mathbf{N} \\
1\end{array}$ & & $\begin{array}{c}\text { Class Interval } \\
\mathbf{2} \\
\end{array}$ & $\begin{array}{c}\text { Mid. Class(H) } \\
3 \\
\end{array}$ & $\begin{array}{c}\text { Ni/year } \\
4\end{array}$ & $\sum_{\mathbf{5}} \mathbf{N}_{\mathrm{i}}$ & $\begin{array}{c}\mathrm{P}(\leq \mathrm{H}) \\
6\end{array}$ & $\begin{array}{l}\mathbf{Q} \\
7\end{array}$ & $\begin{array}{c}Z=\Phi^{-1}(P) \\
8\end{array}$ & $\begin{array}{c}\mathrm{Ln} \mathrm{H} \\
9\end{array}$ & $\begin{array}{l}G \\
10\end{array}$ & $\begin{array}{l}W 2 \\
11 \\
\end{array}$ \\
\hline 1 & 0 & 0.05 & 0.025 & 0 & 0 & 0 & 1 & & -3.68888 & & \\
\hline 2 & 0.05 & 0.1 & 0.075 & 16601 & 16601 & 0.001871 & 0.998129 & -2.89906 & -2.59027 & -1.83754 & -6.28014 \\
\hline 3 & 0.1 & 0.15 & 0.125 & 593412 & 610013 & 0.068765 & 0.931235 & -1.48505 & -2.07944 & -0.98472 & -2.64164 \\
\hline 4 & 0.15 & 0.2 & 0.175 & 1566856 & 2176869 & 0.245393 & 0.754607 & -0.68906 & -1.74297 & -0.33996 & -1.26741 \\
\hline 5 & 0.2 & 0.25 & 0.225 & 1681219 & 3858088 & 0.434913 & 0.565087 & -0.16388 & -1.49165 & 0.183192 & -0.56076 \\
\hline 6 & 0.25 & 0.3 & 0.275 & 1530593 & 5388681 & 0.607454 & 0.392546 & 0.272689 & -1.29098 & 0.696193 & -0.0671 \\
\hline 7 & 0.3 & 0.35 & 0.325 & 1292573 & 6681254 & 0.753162 & 0.246838 & 0.684475 & -1.12393 & 1.260634 & 0.335776 \\
\hline 8 & 0.35 & 0.4 & 0.375 & 981013 & 7662267 & 0.86375 & 0.13625 & 1.097323 & -0.98083 & 1.92092 & 0.689773 \\
\hline 9 & 0.4 & 0.45 & 0.425 & 624935 & 8287202 & 0.934197 & 0.065803 & 1.507802 & -0.85567 & 2.687254 & 1.001034 \\
\hline 10 & 0.45 & 0.5 & 0.475 & 313948 & 8601150 & 0.969588 & 0.030412 & 1.874772 & -0.74444 & 3.477515 & 1.250737 \\
\hline 11 & 0.5 & 0.55 & 0.525 & 149208 & 8750358 & 0.986408 & 0.013592 & 2.208861 & -0.64436 & 4.291428 & 1.458211 \\
\hline 12 & 0.55 & 0.6 & 0.575 & 79272 & 8829630 & 0.995344 & 0.004656 & 2.600383 & -0.55339 & 5.367268 & 1.680753 \\
\hline 13 & 0.6 & 0.65 & 0.625 & 26606 & 8856236 & 0.998343 & 0.001657 & 2.937049 & -0.47 & 6.402063 & 1.85675 \\
\hline 14 & 0.65 & 0.7 & 0.675 & 8347 & 8864583 & 0.999284 & 0.000716 & 3.188195 & -0.39304 & 7.241722 & 1.979909 \\
\hline 15 & 0.7 & 0.75 & 0.725 & 4218 & 8868801 & 0.99976 & 0.00024 & 3.491303 & -0.32158 & 8.333355 & 2.120281 \\
\hline 16 & 0.75 & 0.8 & 0.775 & 2132 & 8870933 & 1 & 0 & & -0.25489 & "“ & “ \\
\hline 17 & 0.8 & 0.85 & 0.825 & & 8870933 & 1 & 0 & & -0.19237 & “ & “ \\
\hline " & ، & ، & " & “ & " & " & " & “ & “ & “ & ، \\
\hline 30 & & & & & & & & & & & \\
\hline
\end{tabular}

Total: $\quad 8,870,933$

Table 3: Probability Distribution of Offshore Hs. Calculations(1989 - 1990)

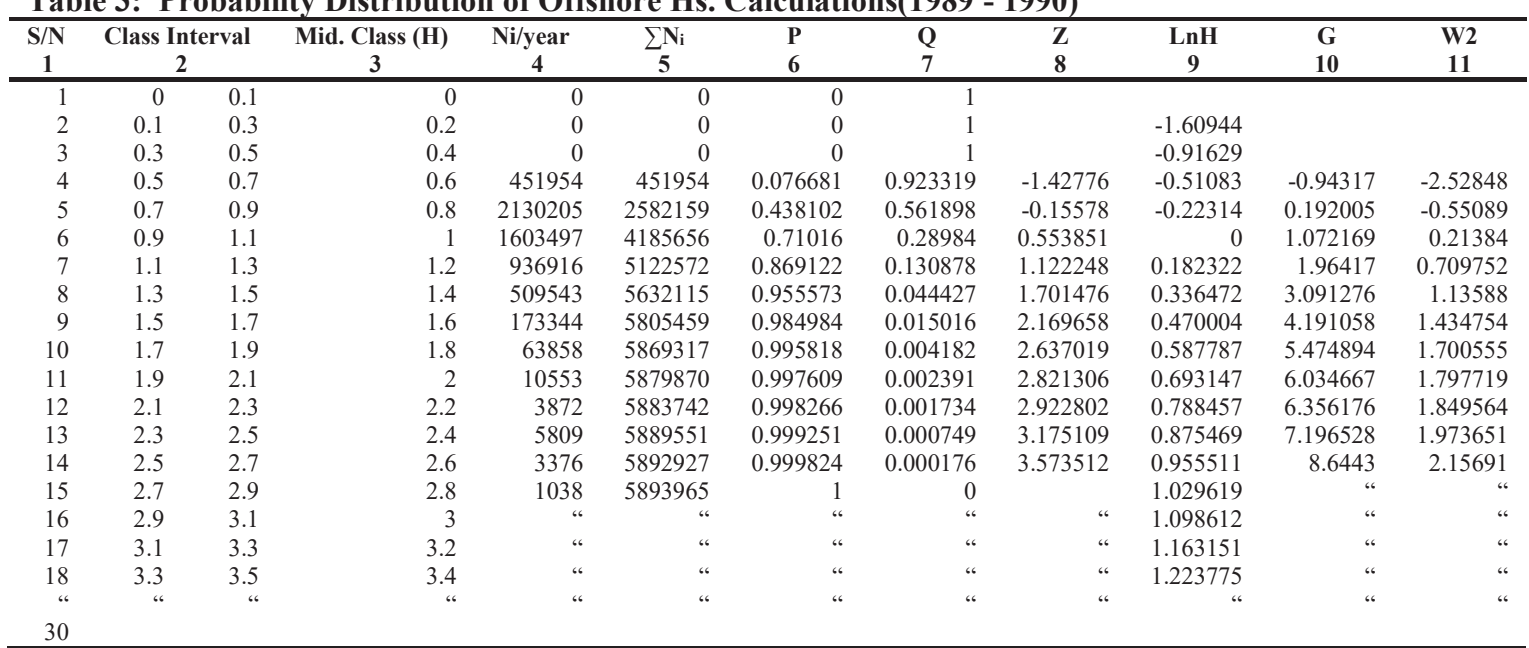

Total : $\quad 5,893,965$

\subsection{Results}

The goodness - of - fit ( GoF) tests have been selected based on wave evaluation criteria mostly cited in literature ( e.g. Bryant et al. 2016, Akpinar et al. 2012). They indicate how well a probability distribution fits the observed wave climate. The results of GoF tests are given in Table5. The recommended performance rating for each test was used to assess each probability distribution. For example, the range of $\mathrm{R}^{2}$ lies between 0 and 1 which describes how much of the observed dispersion is explained by the prediction. A value of zero means not correlation at all whereas a value of 1.0 means a perfect fit (Krause et al., 2005). The range of performance scores index $\left(\mathrm{d}_{1}\right)$ is similar to that of $\mathrm{R}^{2}$ and lies between zero (poor performance) and one (excellent performance). The scatter index (SI) is a normalized measure of error. Lower values of the SI are an indication of the better model performance. The RMSE is a measure of the residuals between the model predictions and measured observations, where larger values indicate greater variance. The RMSE is corrected for bias resulting in RMSE (demeaned) and the other forms of RMSE which includes components of variance and bias as normalized (NRMSE). Accordingly, a perfect model has a bias, RMSE including RMSE (demeaned and normalized RMSE), and SI of 0.0. Based on the above performance rating, the 3 - parameter Weibull distribution is scored 1 with $\mathrm{R}^{2}$ value of 0.9937 in the offshore category. Similarly, the 3-paramter Weibull distribution is also scored 1 with $\mathrm{R}^{2}$ value of 0.9935 being the highest in the inshore category. The inshore and offshore wave climates were scored separately in order to account for the different wave height attenuation processes. Table 6 shows the scored results of each probability distribution. The total score of each distribution was obtained by summing the individual point scores obtained from all the GoF tests (Izinyon and Ajumuka, 2013). The best-fit model for each distribution was selected based on the lowest score obtained as shown in 
Table 7.

Table 5: Results of Goodness - of - fit Tests( GoF)

\begin{tabular}{|c|c|c|c|c|c|c|c|c|c|c|}
\hline \multirow{3}{*}{ GOF } & \multicolumn{9}{|c|}{ Probability Distributions } & \\
\hline & \multicolumn{2}{|c|}{ Rayleigh } & \multicolumn{2}{|c|}{ Log normal } & \multicolumn{2}{|c|}{ FT-1 } & \multicolumn{2}{|c|}{ Weibull 2} & \multicolumn{2}{|c|}{ Weibull3 } \\
\hline & Inshore & Offshore & Inshore & Offshore & Inshore & Offshore & Inshore & Offshore & Inshore & Offshore \\
\hline 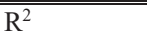 & 0.936 & 0.913 & 0.988 & 0.9912 & 0.986 & 0.9904 & 0.936 & 0.9132 & 0.9935 & 0.9937 \\
\hline RMSE(Dm) & 0.278 & 0.347 & 0.258 & 0.268 & 0.261 & 0.258 & 0.278 & 0.592 & 0.197 & 0.261 \\
\hline NRMSE & 0.127 & 0.122 & 0.073 & 0.044 & 0.053 & 0.036 & 0.127 & 0.222 & 0.146 & 0.041 \\
\hline S.I. & 0.696 & 0.217 & 0.646 & 0.167 & 0.652 & 0.161 & 0.695 & 0.370 & 0.491 & 0.163 \\
\hline P.S.Index & 0.850 & 0.923 & 0.929 & 0.975 & 0.937 & 0.981 & 0.850 & 0.866 & 0.835 & 0.977 \\
\hline
\end{tabular}

Where $\mathrm{R}^{2}$ is coefficient of determination, RMSE(Dm) is RMSE(demeaned), NRMSE is normalized RMSE, S.I. is scatter index and P.S Index is performance score index.

Table 6: Probability distributions of scoring based on Tests( GoF)

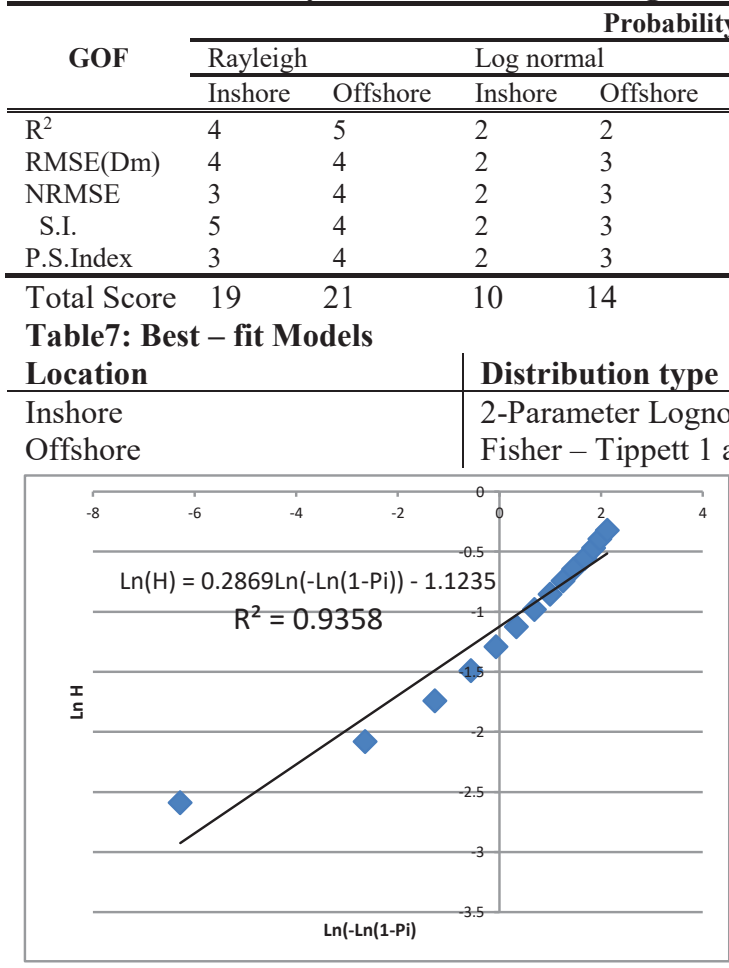

Figure 3 Rayleigh Distribution for Inshore data

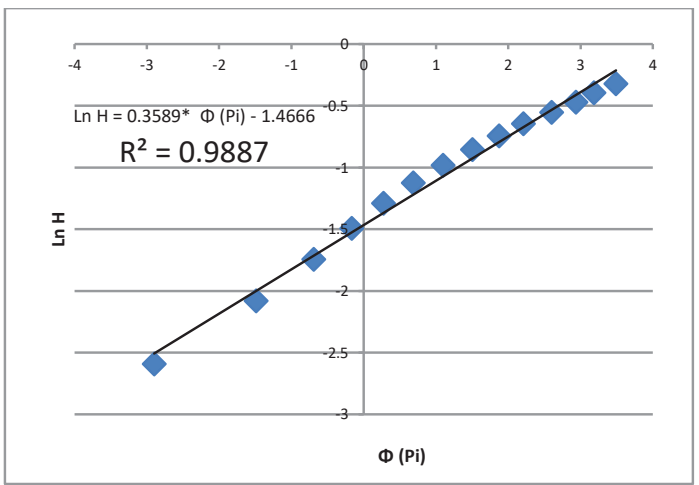

Figure 5 Lognormal Distribution for Inshore Data

\begin{tabular}{llllll}
\multicolumn{2}{c}{ FT-1 } & \multicolumn{2}{l}{ Weibull } & \multicolumn{3}{l}{ Weibull3 } \\
\hline Inshore & Offshore & Inshore & Offshore & Inshore & Offshore \\
\hline 3 & 3 & 4 & 4 & 1 & 1 \\
3 & 1 & 4 & 5 & 1 & 2 \\
1 & 1 & 3 & 5 & 4 & 2 \\
3 & 1 & 4 & 5 & 1 & 2 \\
1 & 1 & 3 & 5 & 4 & 2 \\
\hline 11 & 7 & 18 & 24 & 11 & 9
\end{tabular}

rnal, FT-1, 3-P Weibull distribut.

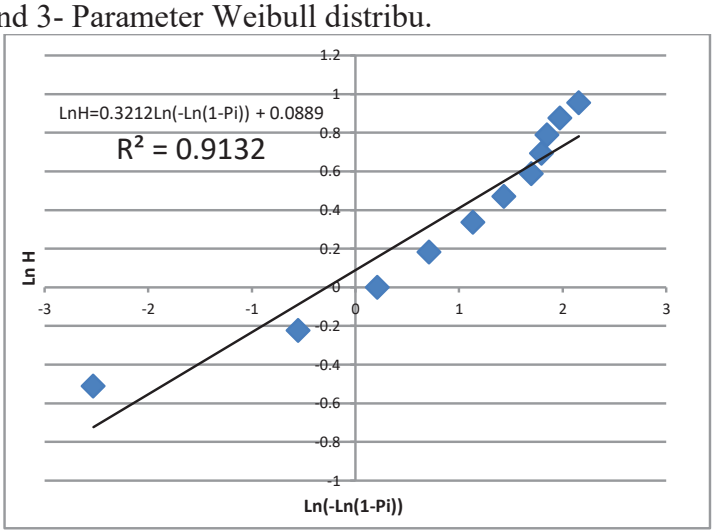

Figure 4 Rayleigh Distribution for Offshore Data

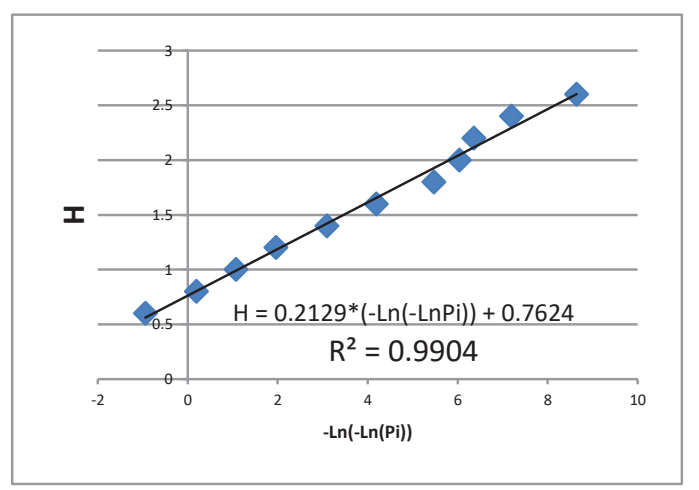

Figure 6 Log normal Distribution for Offshore Data 


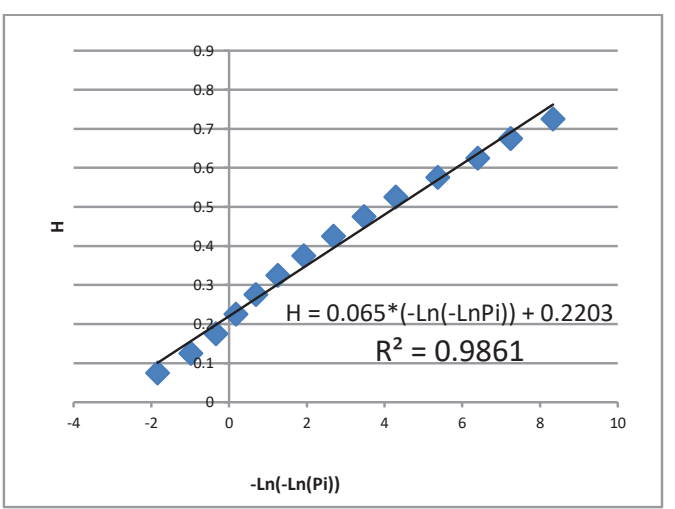

Figure 7 FT - 1 Distribution for Inshore Data

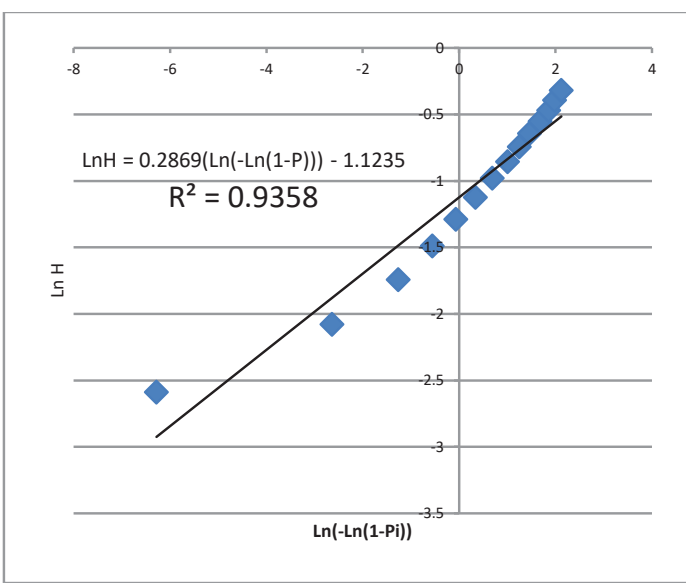

Figure 9 2-Para.Weibull Dist. For Inshore Data

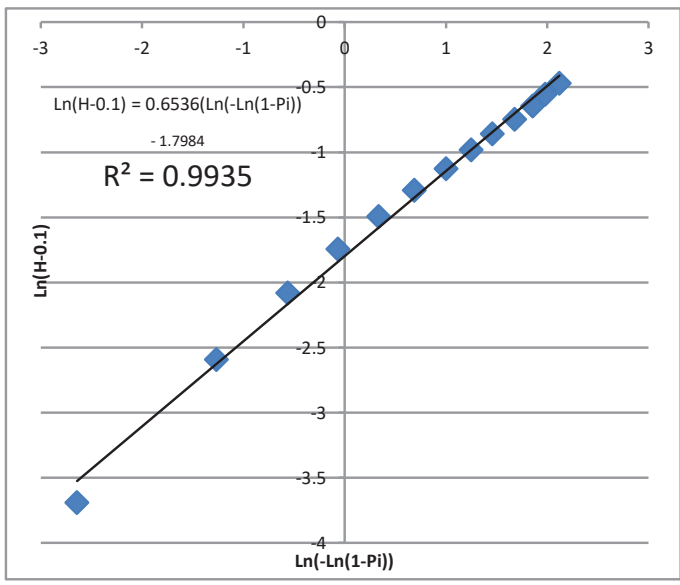

Figure 11 3-Para.Weibull Dist. For Inshore Data

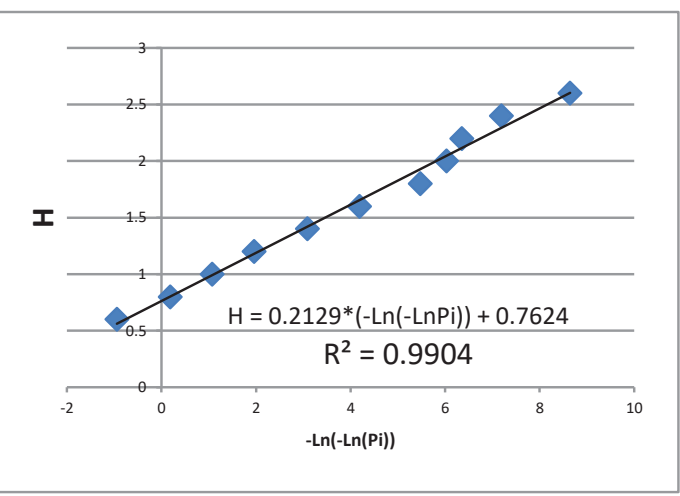

Figure 8 FT - 1 Distribution for Offshore Data

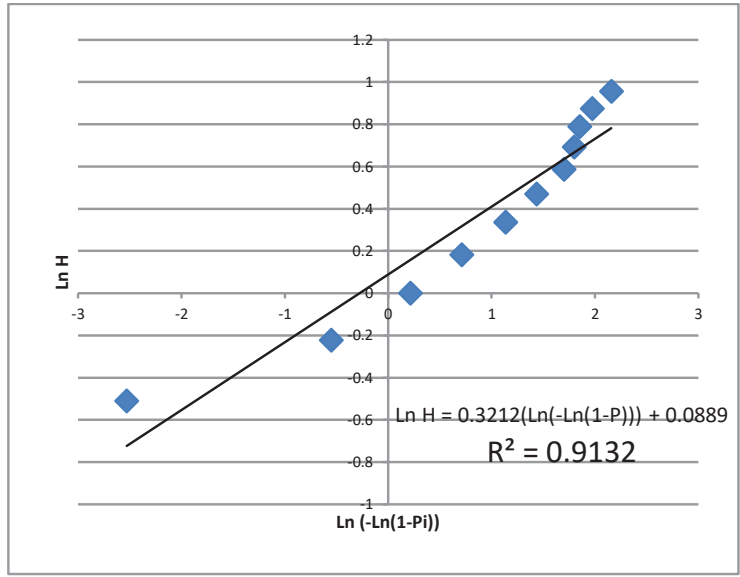

Figure 10 2-Para.Weibull Dist. for Offshore Data

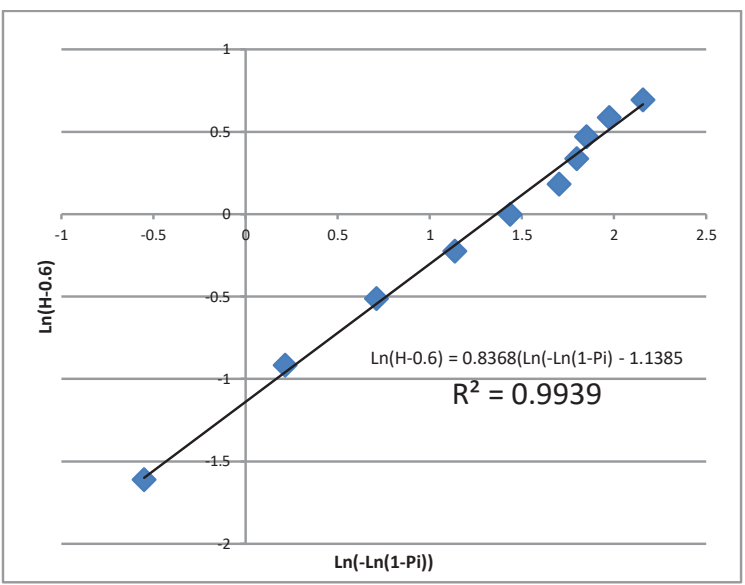

Figure 12 3-Para.Weibull Distrib. for Offshore Data

\subsection{Discussion}

The results obtained in this study agrees with those found under similar geographic settings in other parts of the world. The Nigerian NLNG found 3 - parameter Weibull distribution the best fit for both Inshore and Offshore stations. Conversely this study found 2 - parameter Lognormal the best - fit distribution for the Inshore station. and Fisher - Tippett Type1 the best - fit probability distribution for the Offshore station seconded closely by 3 parameter Weibull distribution. The findings of this report is also in agreement with WMO- No.702( pg. 106) report that Fisher - Tippett Type 1 distribution is a good fit to 3 - hourly data from the North Atlantic and North Sea. WMO- No.702(1989) also recommended 3 - parameter Weibull distribution to be good fit, though it is not 
the best fit in this study. Further, the good performance of 2-parameter Lognormal distribution for the inshore station may be attributed to the absence of seasonal effects in significant wave heights. It has been observed that the Inshore wave climate has a clear periodicity with the 12 - hourly tidal cycle. The Offshore wave climate did not show significant periodicity, implying that the Offshore wave climate is different from the Inshore probably due to the presence of the Bonny bar which separates the two stations, causing wave breaking in front of the Bonny bar (NLNG- 1990)

\subsection{Conclusion}

In this paper, the significant wave heights Inshore and Offshore of Bonny River estuary has been modelled statistically. The probability distribution employed are Rayleigh, 2- parameter Lognormal distribution, Fisher Tippett Type 1,2 - parameter and 3 - parameter Weibull distributions and the goodness -of- fit (GoF) tests are $\mathrm{R}^{2}$, demeaned RMSE, normalized RMSE, Scatter index (SI) and Performance scores index $\left(\mathrm{d}_{1}\right)$ and the performance of each distribution was scored according to the GoF test rating. The distribution that satisfies the performance rating the best is giving a score of 1 , the next is score 2, and so on. The total score of each distribution was obtained by summing all the individual point scores. The distribution that has the lowest score was adjudged the best - fit. In this way, for the Inshore station, the lognormal scored 10, seconded closely by FT-1 and 3-parameter Weibull distribution scoring 11 points each, 2 - parameter Weibull 18, and Rayleigh distribution 19, consequently the best - fit distribution for the Inshore station is 2- parameter Lognormal distribution. Similarly, the FT-1 is the best fit distribution for the Offshore station. The most important outcomes of this study may be summarized as ;

(i)The best - fit probability distribution for the Inshore station is 2-parameter Lognormal distribution with a total score of 10, seconded closely by FT-1, 3-P Weibull distributions having scored of 11 points each.

(ii) The best - fit probability distribution for the Offshore station is FT-1 distribution with a total score of 7 points, seconded closely by 3-Parameter Weibull distributions with a score of 9 points.

(iii)The wave climates Inshore and Offshore are different due to the presence of the Bonny bar which prevents the penetration of Offshore waves.

(iv) Reasoning from (iii) above, the seasonal effects observed Offshore was absence in the Inshore waves.

(v) The waves climate Inshore is mainly due to swell waves.

\section{Acknowledgement}

The author wish to acknowledge with special thanks to Engr. Joseph Enoch for his invaluable Information Technology Support and Mr. Uche Anireh for his type - setting works. I sincerely appreciate your contributions.

\section{REFERENCE}

Akpinar, A., Vledder, G. Ph. Van, Komurcu, M.I, and Ozger, M. 2012. Evaluation of the numerical wave model (SWAN) for the simulation in the black sea. Continental Shelf Research, 50 - 51: 80- 99.

Ardhuin, F., Rodger, E., Bahamin, A.V., Filipot, J.F., Magne, R., Roland, A., van der Westhuysen, A., Queffeulou, P., Lefevre, J.M., Aouf, L. and Colland, F. (2010). "Semiempirical dissipation source functions for ocean waves. Part 1: Definition, calibration, and validation". Journal of Physical Oceanography, (40), 1917 - 1941.

Bryant, M. A., Hesser, T.J. and Jensen, R.E. (2016). "Evaluation Statistics Computed for the Wave Information Studies (WIS)". ERDC/CHL CHETN-1-91. Vicksburg, MS: U.S. Army Engineer Research and Development Center.

Carter, D.J.T., Challenor, P.G., Ewing, J.A., Pitt, E.G., Srokosz, M.A. and Tucker, M.J. (1986). "Estimating Wave Climate Parameters for Engineering Applications." OTH $86286 . \quad$ Institute of Oceanographic Science, Wormley, Godalming, Surrey, England, GU8 5UB.

Chai, T., and Draxler, R.R(2014) “ Root mean square error (RMSE) or mean absolute error(MAE) ? Arguments against avoiding RMSE in the literature" Geoscientific Model Development : $1247-1250$.

Izinyon, O.C. \& Ajumuka, H.N. (2013), "Evaluation of Some Flood Prediction Models for Three Flow Gauging Stations in Upper Benue River Basin in Nigeria- Part 1", Nigeria, Journal of Technology, Vol. 32. No.2, pp. $184-196$.

Nigerian LNG (NLNG) Development Project, "Inshore and Offshore Wave Observations and Analyses”, Report, October, 1990.

Ochi, M.K. (1982), “Stochastic Analysis and Probabilistic Prediction of Random” Advances in Hydroscience, Vol. 13, pp. $218-375$.

Wilmott, C.J., Ackleson, S.G., Davis, R.E., Feddema, J.J., Klink, K.M., Legates, D.R., O’Donnell, J. and Rowe, C.M. (1985). "Statistics for evaluation and comparison of models". Journal of Geographical Research: Oceans 90 (C5): 8995-9005.

WMO - No. 702 (1998). "Guide to Wave Analysis and Forcasting", World Meteorological Organization. 